\title{
Correction to: Global ocean heat content redistribution during the 1998-2012 Interdecadal Pacific Oscillation negative phase
}

\author{
Guillaume Gastineau $^{1}\left[\right.$ [D $\cdot$ Andrew R. Friedman ${ }^{1,2}\left[\right.$ Myriam Khodri $^{1} \cdot$ Jérôme Vialard $^{1}$
}

Published online: 16 July 2020

(c) Springer-Verlag GmbH Germany, part of Springer Nature 2020

\section{Correction to: Climate Dynamics (2019) 53:1187-1208 https://doi.org/10.1007/s00382-018-4387-9}

The wind stress was erroneously post-processed from the ERA-Interim forecast in our study. The daily wind stress field was calculated from accumulated stress every $6 \mathrm{~h}$ with the forecast starting at the reference time $12 \mathrm{~h}$ of the day before. We mistakenly averaged the accumulated stress over the lead times $18 \mathrm{~h}, 24 \mathrm{~h}, 30 \mathrm{~h}$ and $36 \mathrm{~h}$ instead of taking the accumulated quantity at $36 \mathrm{~h}$ minus that at $12 \mathrm{~h}$. This results in our study overestimating wind stress anomalies by a factor of about $19 \%$, though the spatial pattern of the anomalies is identical. Over the Niño 4 region, this results in a 1992-2012 zonal wind stress trend of $-1.6510^{-2} \mathrm{~Pa} \mathrm{dec}^{-1}$ in our study, instead of $-1.39 \mathrm{~Pa} \mathrm{dec}^{-1}$ in the original ERAinterim dataset (Fig. 1). This is consistent with the overall overestimated Niño 3.4 SST interannual variability in our wind-stress-forced simulations (Fig. 1e in the original study).

We, therefore, speculate that the ocean heat uptake associated with the wind stress forcing is also overestimated in the sensitivity experiment presented. The ocean processes found in our study should still apply when using corrected wind stress; however, the exact quantities reported from our experiments should be interpreted with caution.

Publisher's Note Springer Nature remains neutral with regard to jurisdictional claims in published maps and institutional affiliations.

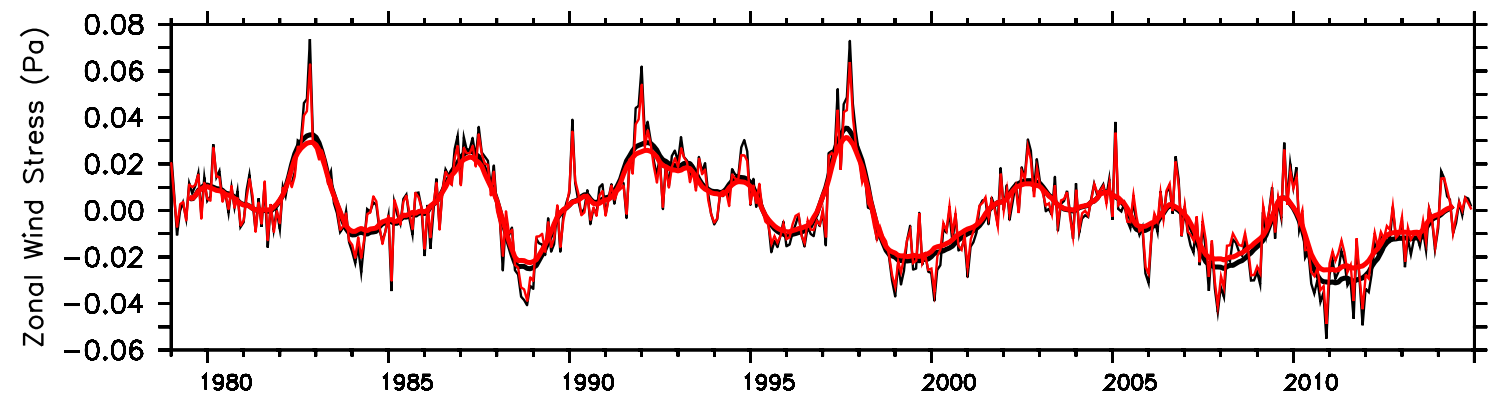

Fig. 1 Monthly Niño 4 zonal wind stress anomalies, in Pa. The black line indicates the zonal wind stress anomaly applied in the W-FULL experiment, in this study. The red line indicates the wind stress from
ERA-Interim. Thin lines are monthly means, while thick lines show the 12-month running means

The original article can be found online at https://doi.org/10.1007/ s00382-018-4387-9.

Guillaume Gastineau

guillaume.gastineau@upmc.fr

Sorbonne-Université, LOCEAN, CNRS/IRD/UPMC/ MNHN, Paris, France

2 Present Address: School of Geosciences, University of Edinburgh, Edinburgh, UK 